\title{
MAPEAMENTO DA CRIMINALIDADE EM LAGUNA/SC Relações entre a ocorrência de crimes e a configuração espacial
}

\author{
Michelle Souza Benedet, Maeve Camargo Waltrick, Julia Kaiper \\ UDESC/UNISUL/USP, UDESC, UDESC \\ arq.michelle@gmail.com, maevewaltrick@hotmail.com, julia_kaiper@hotmail.com
}

\section{RESUMO}

A prevenção da criminalidade pode propiciar bairros e cidades mais seguros absorvendo conceitos de vitalidade urbana e pelas relações com a urbanidade. A motivação desta investigação surgiu para refletir e definir os conceitos sobre como a configuração espacial pode afetar os níveis de seguranças naqueles lugares que acolhem a vida comunitária de seus habitantes. Como recorte de estudo, apresenta-se a área urbana do município de Laguna que apresenta aproximadamente 44.000 habitantes (IBGE, 2016), no Sul de Santa Catarina, buscando verificar as relações de sintaxe espacial com a segurança dos espaços. Neste trabalho será apresentada uma breve revisão bibliográfica, a metodologia e o estudo de caso realizado com base na Teoria da Sintaxe Espacial e dados coletados na Polícia Militar de Santa Catarina.

Palavras-chave: configuração espacial, criminalidade, sintaxe espacial.

\begin{abstract}
Crime prevention can provide safer neighborhoods and cities by absorbing concepts of urban vitality and relationships with urbanity. The motivation of this investigation has arisen to reflect and to define the concepts on how the spatial configuration can affect the levels of security in those places that welcome the community life of its inhabitants. As a study clipping, the urban area of the city of Laguna, which presents approximately 44,000 inhabitants (IBGE, 2016), is presented in the South of Santa Catarina, seeking to verify spatial syntax relationships with space security. This paper will present a brief bibliographic review, methodology and case study based on the Spatial Syntax Theory and data collected at the Military Police of Santa Catarina.
\end{abstract}

Palavras-chave: spatial configuration, criminality, spatial syntax. 


\section{INTRODUÇÃO}

Ao crescerem, as cidades perdem, recuperam, descobrem ou se deparam com novas situações que Ihe atribuem um declínio ou aumento da qualidade de vida. A configuração espacial pode ser considerada um elemento com grande significado que contribui para a maior ou menor ocorrência de crimes em ambientes urbanos.

Esta pesquisa surge do interesse do entendimento da relação entre arquitetura, espaço urbano e criminalidade na cidade de Laguna. Busca-se compreender a relação estabelecida entre a configuração espacial e a ocorrência de crimes através da análise da forma e uso destes espaços, conferindo se existem atributos que contribuem para as ocorrências.

Podemos relacionar a ausência de ocorrências de crimes com a urbanidade dos espaços, entendida como aquilo que qualifica a vida urbana, no sentido da interação entre os cidadãos no espaço coletivo da promoção do encontro e do convívio social (HOLANDA, 2002). Jones e Fanek (1997 apud VIVAN, 2012) indentifcam vários problemas urbanos que são causados pelo declínio da qualidade de vida das nossas cidades, incluindo o aumento da incidência criminal em ambientes urbanos. A segurança dos espaços, públicos e privados, pode ser considerada um atributo da urbanidade e promover a valorização destes pelas pessoas, torna-se uma condição essencial para sua proteção.

Como objeto de estudo apresenta-se a área urbana do município de Laguna, SC, com uma população estimada de 44.982 (IBGE, 2016) e a ocorrência de 2151 crimes e contravenções registrados pela Polícia Militar de Santa Catarina nos últimos 5 (cinco) anos. Os tipos de ocorrências registrados foram furtos, posse e tráfico de drogas, homicídios, posse irregular de arma de fogo, estupro e outros, conforme a figura 1. 0 gráfico apresenta os tipos de crimes com maior incidência na cidade, onde os furtos lideram a lista, apresentando índice de ocorrência de $51 \%$; o segundo e terceiro lugar dizem respeito à posse e tráfico de drogas, ocupando $38 \%$ do total registrado.

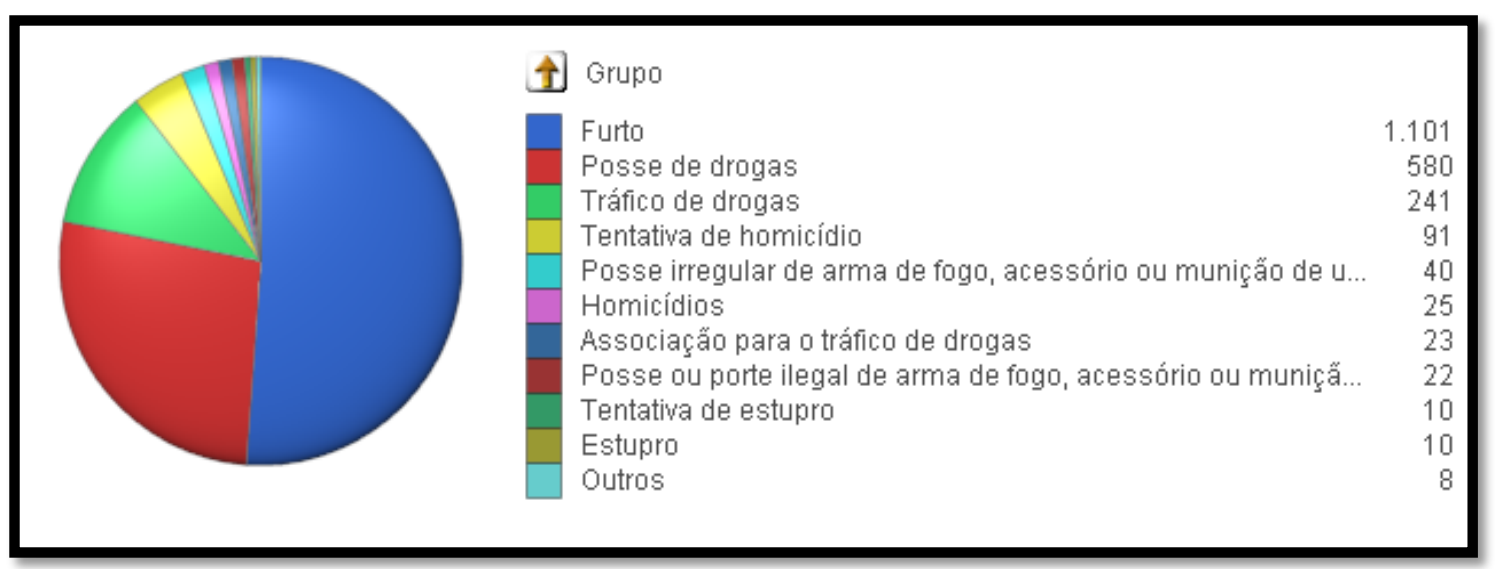

Figura 1 - Ocorrências registradas nos últimos cinco anos (2011-2016) em Laguna/SC (PMSC, 2016)

Sobre os usos das edificações, a mistura pode gerar usos mais intensos nos locais pelas pessoas em vários períodos do dia proporcionando mais segurança, de um lado; mas por outro, pode ser o local onde há maior predileção dos bandidos por ter maior movimentação de pessoas. As áreas monofuncionais prejudicam o dinamismo em todas as horas do dia e noite, facilitando a ocorrência. A tipologia edificatória também pode prejudicar a segurança, por exemplo, o uso de fachadas cegas diminui o número de aberturas para a rua, os "olhos da rua", conforme destaca Jacobs (2000) e, por consequência, facilita a prática de crimes.

A figura 2 mostra os horários de maior criminalidade em Laguna: nota-se que o período compreendido entre $16 \mathrm{~h}$ e $18 \mathrm{~h}$ - horário em que os moradores estão fora de casa é o mais periogoso, seguido do horário entre as $23 \mathrm{~h}$ e $0 \mathrm{~h}$ - horário que estão dormindo e áreas monofuncionais comerciais ficam suscetíveis aos crimes. 


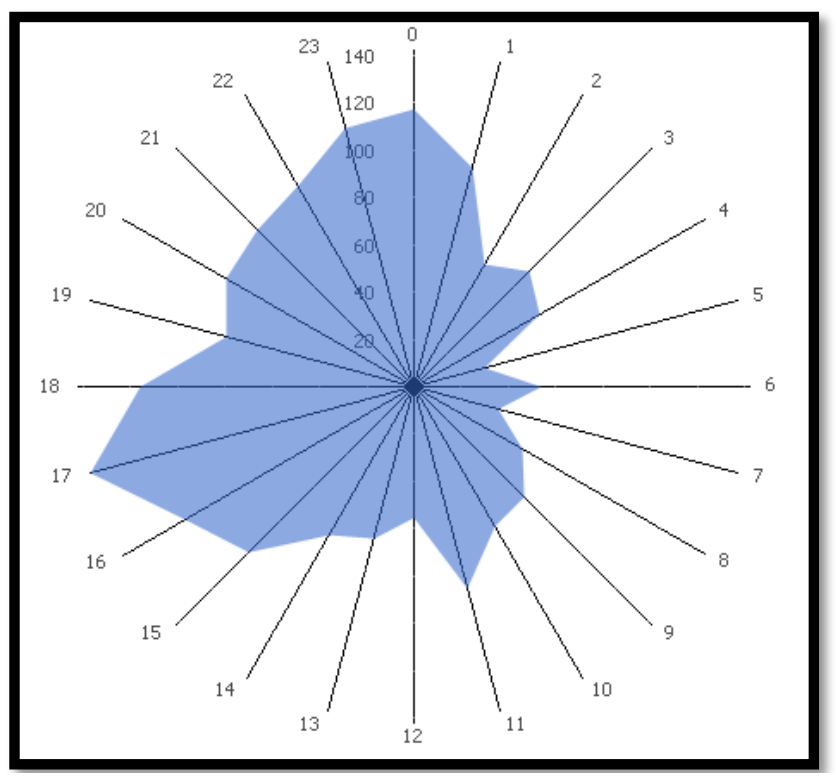

Figura 2 - Delitos por hora cheia dos últimos cinco anos em Laguna (PMSC, 2016)

A configuração espacial pode gerar impactos no espaço urbano, tornando-os mais suscetíveis à criminalidade ou não. As quadras longas e terrenos vazios geram impactos negativos no que diz respeito à ocorrência de crimes. As vias podem variar entre integradas e segregadas, proporcionando uma maior segurança.

A análise será abordada do ponto de vista morfológico, buscando estabelecer as relações entre as ocorrências de crimes e a configuração espacial, definindo quais são os condicionantes físicos que configuram a suscetibilidade à prática de crimes.

O objetivo da pesquisa é verificar a relação entre a configuração espacial e a ocorrência de crimes na área urbana de Laguna, representadas pelas medidas da sintaxe espacial e complementadas com informações sobre os usos do solo.

\section{METODOLOGIA DA PESQUISA}

Os métodos e técnicas a serem empregadas consolidarão o conhecimento técnico a respeito da relação entre a configuração espacial, por meio da morfologia urbana, e a ocorrência de crimes, contribuindo no entendimento de quais fatores influenciam a segurança dos espaços, públicos e privados. A metodologia do trabalho é apresentada a seguir.

a) Revisão bibliográfica: a pesquisa teórica estará relacionada aos fatores que influenciam a segurança dos espaços urbanos, a morfologia urbana e a teoria da sintaxe espacial, se pautando nos autores Jane Jacobs, Jan Gehl e Bill Hillier. Por meio da morfologia urbana e da teoria da sintaxe espacial buscaremos entender a forma de capturar teórica e metodologicamente a segurança dos espaços. A abordagem parte do princípio de que a complexidade urbana deriva dos condicionalismos do espaço cuja ordem e expressão formal é adquirida em função de um processo social. Nesta perspectiva, Heitor (2001) propõe que a leitura morfológica da cidade seja estabelecida a partir do relacionamento das características formais do espaço com as práticas sociais e há, portanto, que identificar e interpretar na forma urbana as regras implícitas da sua organização.

b) Documentação indireta - pesquisa documental: a documentação indireta consiste na busca de informações para o levantamento de informações, realizada através de materiais que ainda não têm um tratamento analítico ou que podem ser reelaborados de acordo com os objetivos da pesquisa. A documentação indireta será empregada no intuito de levantar dados, informações e documentos relacionados às ocorrências de crimes, obtendo informações e conhecimentos sobre o objeto analisado. A prática desse trabalho se dedica, fundamentalmente, à construção de dados empíricos de um estudo, seja ele de pesquisa voltada para a produção e/ou para a avaliação de conhecimento. A documentação indireta irá coletar dados registrados pela Polícia Militar de Santa Catarina sobre as 
ocorrências de crimes e contravenções (furtos, posse e tráfico de drogas, homicídios, posse irregular de arma de fogo, estupro e outros) na cidade de Laguna.

c) Teoria da Sintaxe Espacial: a Teoria da Sintaxe Espacial é utilizada para representar o espaço e compreender os fenômenos espaciais, sistematizando as informações. Para os criadores, a teoria sintática trata do estabelecimento de padrões e relações compostos essencialmente de barreiras e de permeabilidades de diversos tipos, nas organizações espaciais humanas, seja na forma de assentamentos, seja na forma de edifícios (HILLIER, HANSON, 1984). De acordo com Holanda (2002), a teoria procura construir um modelo conceitual pelo qual a relação pode ser investigada na base do conteúdo social dos padrões espaciais e do conteúdo espacial dos padrões sociais tentando estabelecer, por meio de uma nova definição de ordem espacial como restrições num espaço aleatório, um método de análise de padrões espaciais, com ênfase na relação entre as mórficas e padrões globais. Nesta pesquisa serão elaborados mapas sintáticos de integração (global e R3) referentes à malha urbana do município de Laguna com a localização da ocorrência de crimes entre o período de agosto de 2015 e agosto de 2016, com base nos dados da PMSC. A integração global medirá a integração a partir da profundidade de cada espaço com relação ao sistema todo e a integração local (R3), medirá a profundidade de cada espaço em relação a um outro do sistema que apresente a distância de até 3 (três) passos topológicos.

d) Documentação direta - pesquisa de campo: a técnica da documentação direta, por meio da pesquisa de campo, é empregada para levantar dados no "próprio local onde os fenômenos ocorrem" (LAKATOS, 2010). Serão coletadas, por meio desta técnica, as informações sobre os elementos espaciais referentes às áreas onde ocorreram maior número de crimes. Será realizado levantamento do uso do solo que deve incluir o registro das atividades em todos os níveis e pavimentos, além de observações relacionadas à variedade, distribuição, complementaridade e distribuição temporal e; 0 levantamento das características tipológicas das edificações nas 5 (cinco) ruas com maior ocorrência de crimes entre 2015 e 2016 e incluirá a análise dos elementos das fachadas, suas aberturas e transições entre públicos e privados. O resultado será registrado em forma de texto analítico e imagens.

a) Processamento e análise dos resultados: a análise dos resultados pretende avaliar qualitativamente as condições para ocorrência de criminalidade, em Laguna, e será apresentada de maneira descritiva.

Como variáveis dependentes da pesquisa estão as ocorrências de crimes (furtos, posse e tráfico de drogas, homicídios, posse irregular de arma de fogo, estupro e outros) ocorridos em Laguna, durante o ano de 2015 e 2016 e; como variáveis independentes consideramos os aspectos de visibilidade das edificações e características da malha urbana constantes nos locais das ocorrências analisadas (uso do solo, valores da sintaxe espacial e faixas de renda).

\section{RELAÇÕES ENTRE AS CONDIÇÕES PARA SEGURANÇA DAS CIDADES E A CONFIGURAÇÃO ESPACIAL}

A base conceitual da pesquisa se estabelece a partir da definição estabelecida por Jacobs (2000) na qual afirma que o uso ativo de uma área gera segurança, considerando as ruas com movimentação de pessoas mais seguras. A Teoria da Sintaxe Espacial pretende-se estudar com o propósito para análise, diagnóstico, prescrição e programação da segurança dos espaços, públicos e privados.

Considerando os lugares como os ambientes que ganham significados através da ocupação ou apropriação do homem, deve-se destacar a particularidade de cada lugar. De acordo com Crichyno (1996), a paisagem revela um leque de diversidade nos padrões culturais e estéticos inerentes às expressões contidas no imaginário social que encontram significados em valores e apropriações distintas. Encontramos essa diversidade no objeto de estudo e vamos buscar relacionar com a situação encontrada em cada bairro analisado em Laguna.

Esta seção faz um levantamento de autores que estudam aspectos de segurança e os métodos e técnicas para sua verificação e levantamento. Eles serão aqui apresentados por ordem cronológica de seus principais estudos. 


\subsection{Jane Jacobs}

Jacobs (2000) aborda em seu livro "Morte e Vida das Grandes Cidades" elementos que são fundamentais para garantir a vitalidade urbana, a diversidade: mescla de usos e usuários, edificações de idades e estado de conservação variados, quadras curtas e necessidade de concentração, componentes essenciais para a segurança dos espaços urbanos.

a) Mescla de usos e usuários - as diferentes funções devem "garantir a presença de pessoas que saiam de casa em horários diferentes e estejam nos lugares por motivos diferentes, mas sejam capazes de utilizar boa parte da infraestrutura" (Jacobs, 2000:167). Os usos principais devem funcionar como âncoras e atrair as pessoas a esses lugares específicos e a combinação de diferentes usos principais deve funcionar como uma complementaridade e não uma justaposição.

b) Necessidade de quadras curtas - as quadras curtas garantem uma escolha ampla de percursos e trajetos se cruzando e se entrelaçando em vez de serem isolados. Oferecem pontos viáveis para crescimento das atividades comerciais, através da distribuição e comodidade de sua localização, propiciando uma rede de usos combinados e complexos entre os usuários do bairro gerando diversidade.

c) Combinação de edifícios com idades e estados de conservação variados - a combinação de edifícios novos e antigos garante uma variedade de tipos de negócios com maior e menor poder de investimento. As empresas menores, necessárias para segurança e vitalidade dos bairros, conseguem melhor se instalar em prédios antigos. A diversidade depende dessa mistura de empresas com rendimentos altos, médios e baixos.

d) Necessidade de concentração - a concentração de pessoas é um dos critérios principais para indicar que um lugar possui urbanidade, por consequência a segurança. A atividade residencial precisa ser complementada com outros usos principais de modo que haja concentração de pessoas nas ruas em todas as horas do dia garantindo, também, a existência de infraestrutura nos lugares habitados. Para Jacobs, o objetivo é promover a vida urbana à população urbana, sob concentrações bastante densas e diversificadas.

Com a teoria de Jacobs fica claro que o nível de segurança do espaço urbano depende do grau de vitalidade urbana ali presente. Outros elementos que garantem a segurança dos espaços, conforme a autora, é a vigilância dos moradores e pedestres de forma casual, referidos como "olhos da rua", definição clara entre território público e privado e o uso contínuo das calçadas. Com relação ao método de pesquisa, Jacobs se utiliza das observações das pessoas e fatos que aconteceram em diversos bairros, especialmente onde ela morava - no Greenwich Village, em Nova York.

\subsection{A segurança do espaço urbano para Jan Gehl}

Gehl destaca em suas pesquisas que a qualidade urbana de uma cidade é medida pela quantidade e qualidade do espaço público para pedestres. Seus estudos apontam para uma otimização dos atrativos públicos e as atitudes para acolher uma vida social rica e segura que depende de três fatores: vida social, espaço público e edifícios - nesta ordem sequencial. Para Gehl (2006:21), "a presença de outras pessoas, de atividades e acontecimentos, de inspiração e estímulos, supõe uma das qualidades mais importantes dos espaços públicos".

Gehl (2013) destaca que um bom desenho urbano que facilite o deslocamento das pessoas, contribui à sensação de segurança, observando que o fato das pessoas encontrarem a sua destinação final de forma direta, sem grandes desvios e hesitações, torna-se um sinal de qualidade urbana e, por consequência, mais seguro. As noções de segurança irão influenciar na utilização dos espaços comuns da cidade e essa sensação de sentir-se seguro encontra conexão clara com a vitalidade das cidades.

Na sua publicação New City Life (2006), Gehl, Gemzoe et al apresentam 12 critérios de qualidade para o espaço público divididos em 3 categorias: proteção (contra tráfego e acidentes, contra crime e violência e contra experiências sensoriais desagradáveis); conforto (oportunidades para caminhar, para ficar em pé/permanecer e para sentar) e; prazer (escala, oportunidades para aproveitar os aspectos positivos do clima e experiência sensorial positiva).

Nas suas pesquisas utiliza técnicas de observação para levantamento de fluxo e atividades das pessoas identificando o tráfego de pedestres e as atividades estacionárias que ocorrem no seu entorno. Também utiliza, de maneira menos frequente, entrevistas. 


\subsection{Bill Hillier e a Sintaxe Espacial}

Assim como a teoria de Jacobs, Hillier defende que a urbanidade está relacionada com a vitalidade dos espaços, entendida como a presença de maior ou menor número de pessoas em um espaço público. Os espaços sintaticamente mais integrados são mais carregados de urbanidade na escala global e tendem a ser aqueles com mais vitalidade.

Para este estudo, Hillier e seus colegas da Bartlett School of Graduate Studies, de Londres, propuseram a Teoria da Sintaxe Espacial visando compreender as relações entre a configuração espacial das cidades e edifícios e o modo como as pessoas permanecem ou se movem nos espaços.

Hillier et al (1983), no artigo Space Syntax, descreve os elementos da urbanidade, envolvendo áreas de habitação social que aconteciam na Inglaterra no início dos anos 1980, presente em três condições:

1) A organização global do espaço atuando como um meio através do qual cidade e áreas urbanas podem tornar-se potentes mecanismos capazes de gerar, sustentar e controlar os padrões de movimento de pessoas;

2) A escala ou arranjo global do espaço é determinante no modo como o espaço é apropriado pelas pessoas, garantindo ou não a vitalidade dos espaços públicos;

3) A arquitetura, a escala local e o modo como o espaço público é constituído é o terceiro elemento que garante a urbanidade de uma área.

Com relação à segurança dos espaços, Hillier e Shu (1999) indicam que as ocorrências de assaltos são mais frequentes nas vias mais segregadas e menos frequentes nas vias mais integradas. Para os autores, as pessoas sentem-se mais seguras com áreas onde existem mais transeuntes. Em contraponto a isso, em uma pesquisa em 2002, Hillier verifica que a maior concentração de crimes acontecia numa avenida principal, na área comercial, concluindo que os crimes ocorrem onde há oportunidades para ocorrer. Os assaltantes preferem locais mais integrados globalmente e segregados localmente (HILLIER, 2002).

Hillier utiliza nas suas pesquisas para determinar a urbanidade de um local a Teoria da Sintaxe Espacial criada por ele e seus colegas na década de 1980. Esta teoria busca descrever as configurações dos traçados e as relações entre espaços públicos e privados, através de medidas quantitativas. Para Hillier, a sintaxe estuda as relações entre espaço artificial e sociedade, conteúdo social dos padrões espaciais e conteúdo espacial dos padrões sociais.

\subsubsection{A Teoria da Sintaxe Espacial}

A Teoria da Sintaxe Espacial proposta por Hillier e Hanson (1984) verifica a configuração espacial, por meio de fórmulas matemáticas, comparações e análises estatísticas. Por meio dos mapas axiais é descrita a acessibilidade, entendida como a possibilidade de acesso aos lugares e as implicações nos padrões de movimento, presença de pessoas e usos dos espaços. O espaço é medido considerando as propriedades espaciais descritas a seguir, conforme Hillier et al (1983):

a) Axialidade verifica a inserção no sistema espacial do menor número de linhas retas que passam através de todos os espaços convexos. O mapa axial é o conjunto de linhas retas, as mais longas e em menor quantidade, que podem ser traçadas sobre os espaços convexos do mapa. Este mapa serve de base para outras análises sintáticas;

b) Integração mensura o nível de profundidade de uma linha no sistema, em relação a todas outras. Os espaços mais integrados são aqueles em são necessários menos passos para se chegar a todos os outros, e os mais segregados são aqueles que estão mais profundos sendo necessário um maior número de passos para se chegar até eles;

c) Conectividade afere quantos nós são acessíveis, de forma direta, a partir dele próprio, em um determinado espaço;

d) Escolha global indica a frequência que cada linha é usada e está localizada a menos passos das outras do sistema;

e) Controle mensura o grau de controle de acesso de um espaço para seus vizinhos, feito a partir da soma das reciprocidades de conectividades entre vizinhos. Um espaço que só tenha uma possibilidade de conexão terá valor de controle 1 , se tiver duas formas de conexão terá valor $1 / 2 \mathrm{e}$ assim por diante; 
f) Inteligibilidade mede a conexão entre conectividade e valor de integração indicando o que visualmente pode ser visto através de uma linha e, de acordo com seu grau de integração, o que isto significa para o sistema como um todo;

g) Convexidade verifica as barreiras e perímetros dos espaços convexos e as transições entre eles e os espaços fechados. A análise geralmente é feita em um lugar de pequena escala - um trecho de rua, uma praça, verificando as fronteiras invisíveis entre os lugares;

h) Isovistas é um mapa onde, a partir de um determinado espaço, manifesta-se a soma dos possíveis espaços visíveis, revelando o grau de controle, do ponto de vista visual, que se pode ter de determinado espaço.

Com as medidas de acessibilidade é possível verificar a integração que pode ser global ou local. A integração global relaciona cada linha do sistema com todas as demais e a integração local, ou R3, é a medida que relacionada cada linha as que se limitam a até 3 linhas de distância dela. Nesta pesquisa serão verificadas as medidas de integração, global e local, da cidade de Laguna para verificação da correlação com a ocorrência de crimes. Essas medidas podem indicar potencial em movimento: as cores quentes (vermelho, alaranjada e amarelo) apresentam maior valor de integração e as cores frias (azul e verde) demonstram menor valor de integração.

Com o mapa axial de integração é possível verificar também a segregação, sendo caracterizada pelas vias menos acessíveis do sistema, representadas pela sintaxe espacial por linhas com cores frias - verde e azul. Os espaços mais segregados apresentam maior dificuldade de acesso, necessitando de mais espaços intermediários para serem acessados.

A medida de profundidade existe para verificar a necessidade de espaços intermediários para se ir de um espaço para o outro. A medida de conectividade mede o número de linhas que se interceptam com cada linha do sistema.

A inteligibilidade é a medida que permite a compreensão do sistema do todo a partir das partes. Do ponto de vista do movimento das pessoas demonstra como a parte do sistema se relaciona com o todo e como isto afeta o padrão de movimento.

\section{ESTUDO DE CASO}

Os dados coletados no Batalhão da Polícia Militar de Santa Catarina serviram para identificar e caracterizar a ocorrência de crimes criminalidade no perímetro urbano do município de Laguna. Foram disponibilizadas as ocorrências de crimes que ocorreram no período de 5 anos (2012-2016) com dados identificados por bairros e ruas, mas sem localização exata da ocorrência e dados dos últimos 12 meses (agosto/2015 a agosto/2016) com a identificação dos locais dos crimes ou tentativa deles.

A figura 3 demonstra o gráfico com a porcentagem da ocorrência de crimes distribuídas por bairros de Laguna, nota-se que o bairro Mar Grosso lidera a quantidade de crimes registrados. Esse fato pode ocorrer devido a ser um bairro de veraneio com somente $31 \%$ ocupados, conforme dados do IBGE (2010). 


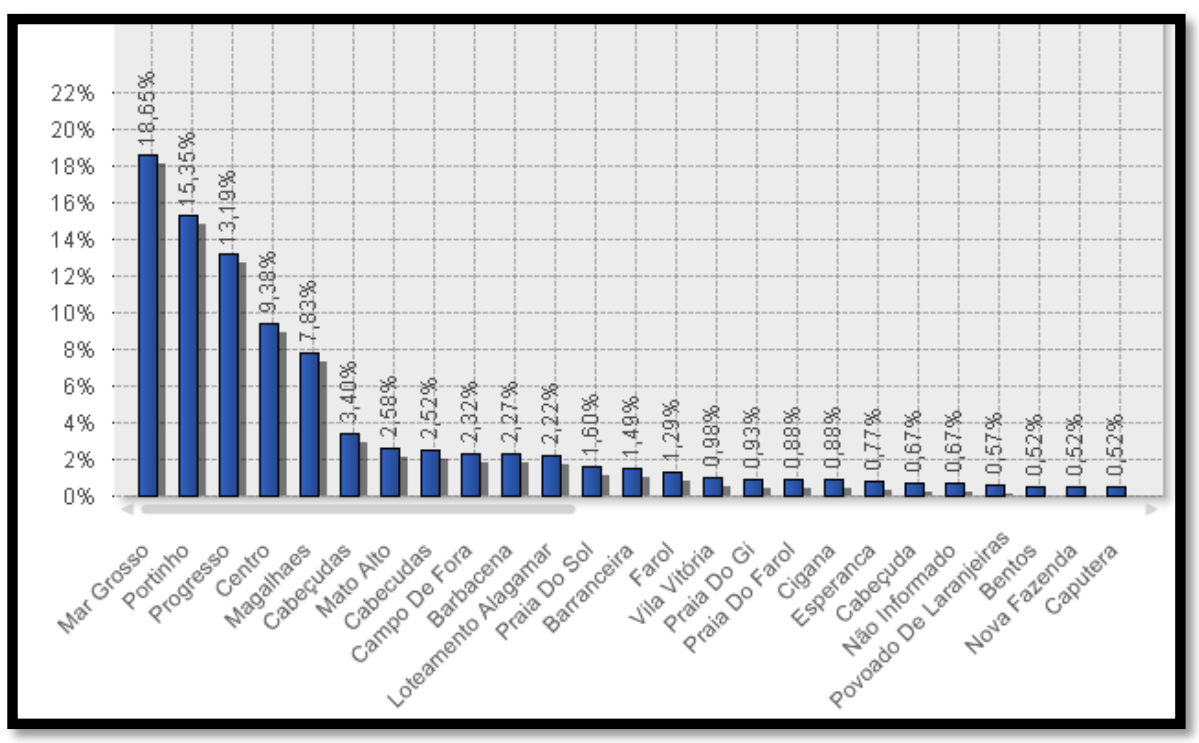

Figura 3 - Porcentagem de ocorrências por bairros nos últimos cinco anos em Laguna (PMSC, 2016)

As figuras 4 e 5 mostram a indiciência de ocorrência de crimes em relação ao dia da semana e ao mês. Notase que os meses de dezembro, janeiro e fevereiro lideram as estatístas com maior indíce de criminalidade e os dias de finais de semana com taxa mais alta em relação aos demais.

Estes dados indicam que a criminalidade está ligada aos momentos de lazer, uma vez que o maior índice de casos deu-se no período de verão, estação de maior número populacional em Laguna, e durante o final de semana. Os números indicam também que o excesso de movimento apresenta forte influência na ocorrência de crimes na cidade.
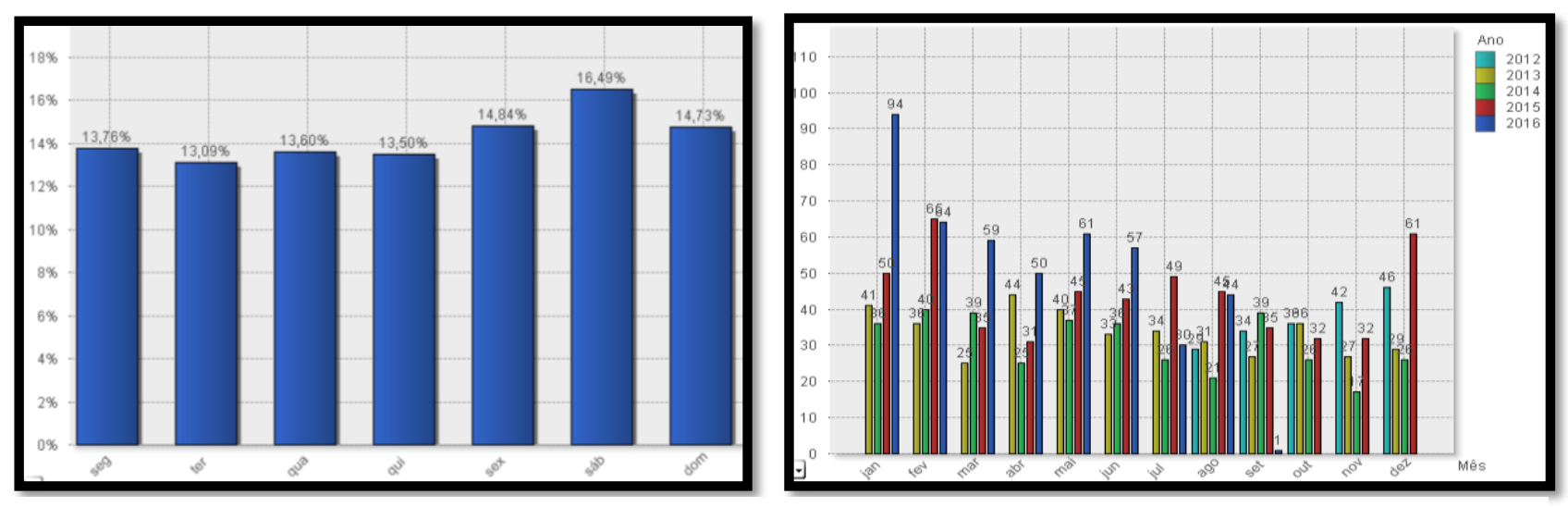

Figuras 4 e 5 - Ocorrências por dia de semana e por mês nos últimos cinco anos em Laguna (PMSC, 2016)

Outra verificação feita foi a relação da ocorrência de crimes com a renda média salarial do bairro, na figura 6 , pode-se perceber que não há uma relação entre maiores rendas familiares com maior ou menor ocorrência de crimes, concluindo-se que a classe social predominante dos bairros não contribuem para o acontecimento da criminalidade. 


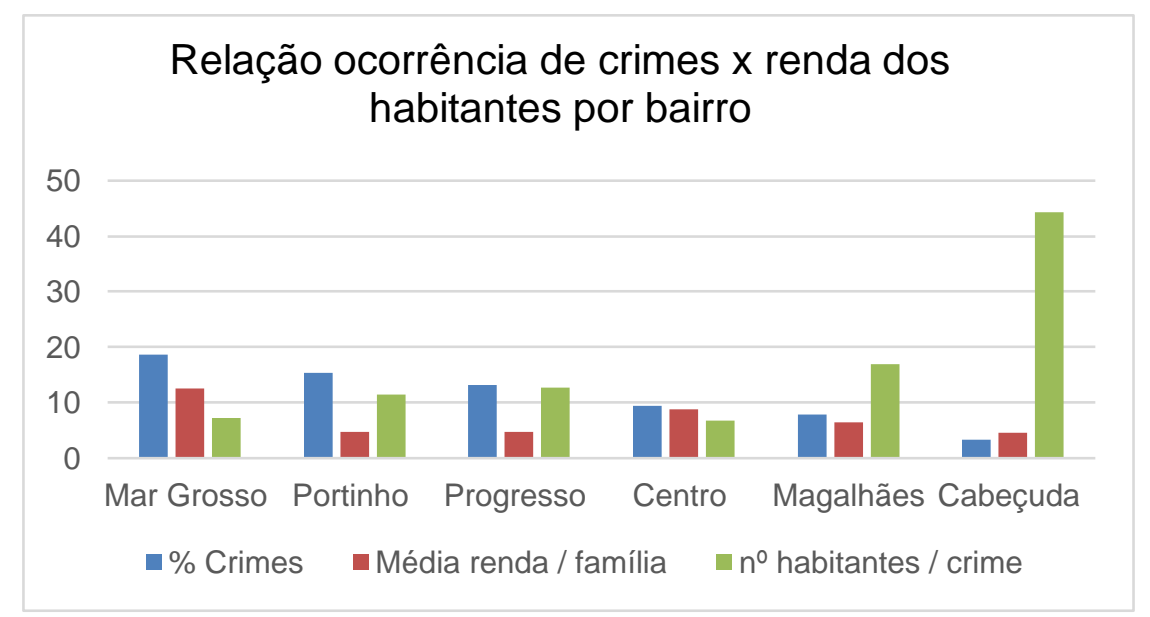

Figura 6 - Relação entre ocorrência de crimes e rendas familiares médias (Elaboração própria a partir de dados da PMSC - 2016 e IBGE - 2016)

Para análise configuracional e sua relação com a criminalidade foram elaborados os mapas sintáticos de integração (global e R3) referentes à malha urbana do município de Laguna com a localização da ocorrência de crimes entre o período de agosto de 2015 e agosto de 2016. As medidas de integração foram retiradas do mapa axial, através do programa Depthmap.

Através do mapa de integração global pode-se perceber como são realizados a movimentação e o uso dos espaços internos e externos, as avenidas Marrozinho e Colombo Machado Sales aparecem como os eixos mais integrados do sistema. A avenida Marrozinho é uma das vias principais de ligação com o bairro Mar Grosso, porém é configurada com grandes vazios urbanos. O mapa de integração local ou R3 demonstra que as vias mais integradas localmente é a Av. Calistrato Muller Salles e Av. São Joaquim. A Avenida Calistrato Muller Salles é uma via comercial de acesso à cidade e com ligação com a BR-101.

Nas análises de integração global e local da cidade de Laguna foram localizados os crimes ocorridos, no período de análise (agosto/2015 a agosto/2016). Com o símbolo de uma sirene estão localizados os pontos exatos da criminalidade em três tamanhos (símbolo menor - ocorrência de 1 a 3 crimes; símbolo médio ocorrência de 4 a 8 crimes e; símboo maior - ocorrência de mais de 9 crimes no mesmo local).

Em relação ao perímetro estudado, no mapa de integração global (figura 7), existem mais vias com integração média comparadas com a totalidade das vias, observa-se que os crimes acontecem predominantemente em vias com média integração, sugerindo que áreas segregadas não são sinônimo de mais crimes, conforme Jacobs e Hillier, em algumas pesquisas, aponta. Os crimes registrados são caracterizados pela média (predominante) e alta integração, ou seja, vias com maiores movimentações.

No mapa de integração local ou R3 (figura 8), existe um equilíbrio de vias com integração média e baixa comparadas com a totalidade das vias e poucas vias com alta integração. Os crimes também se distribuíram de forma homogênea, ocorrendo em vias de diferentes graus de integração local - baixa, média e alta integração. O centro da cidade apresenta um baixo grau de integração local e nele acontece uma grande incidência de crimes. 


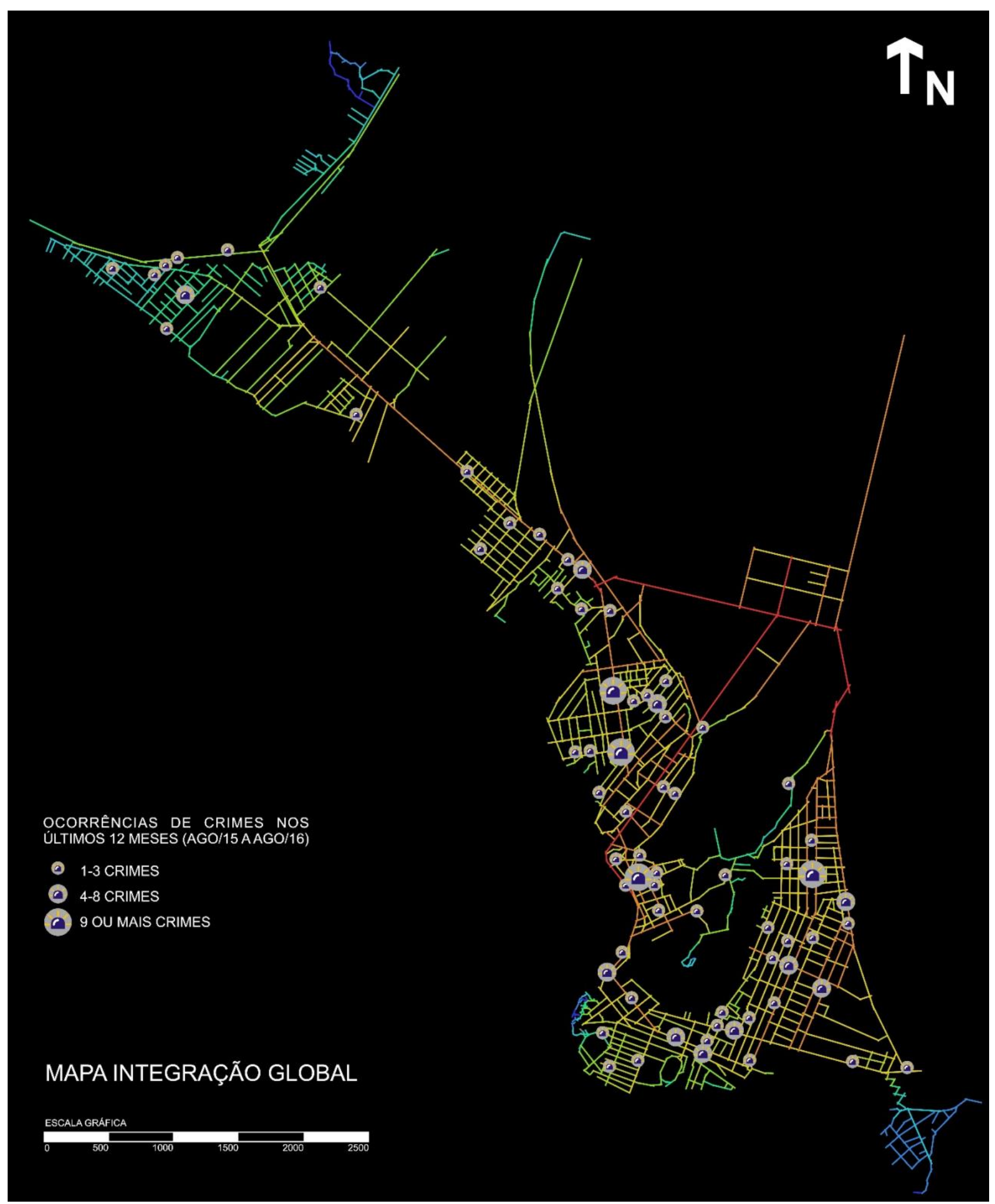

Figura 7 - Mapa de integração global com ocorrência de crimes em Laguna/SC

(Elaboração própria a partir de dados da PMSC (2016) e programa Dephtmap) 


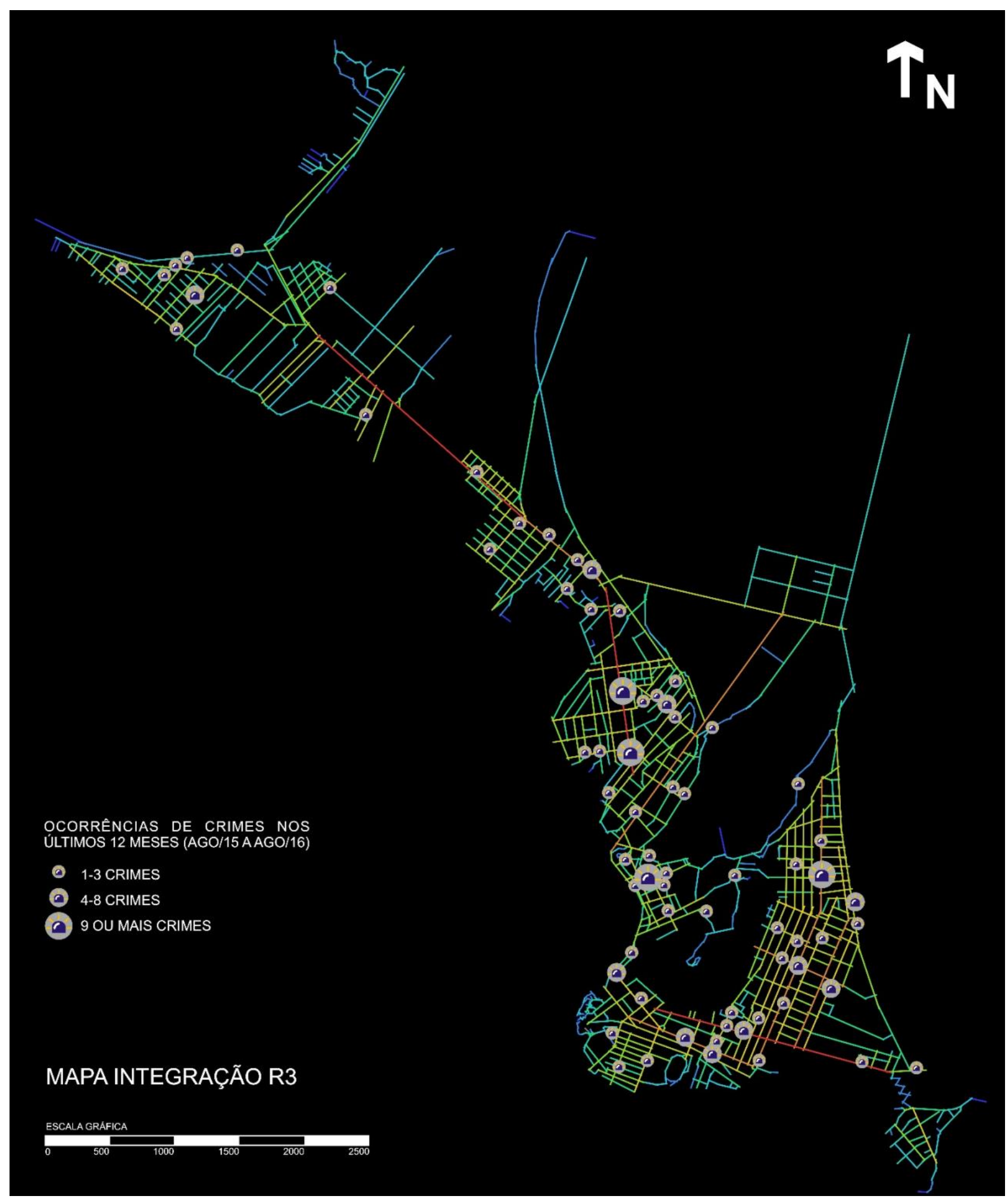

Figura 8 - Mapa de integração local ou R3 com ocorrência de crimes em Laguna/SC

(Elaboração própria a partir de dados da PMSC (2016) e programa Dephtmap)

Com as análises acima não se verificou a relação entre as características sintáticas de altos níveis de segregação com maior ocorrência de crimes. Tanto na integração global como na local, é comprovado que não existe um único padrão existente para a criminalidade, nem sempre o maior número de ligações está relacionado com o menor número de ocorrências de crimes, assim como o contrário. Porém, pode-se verificar que existe uma relação existente entre o alto nível de integração do espaço e a escolha pelo criminoso devido ao fato de maior concentração de vítimas e facilidade para escapar do crime. 
Outra verificação feita foram as características de uso das edificações nas cinco vias com maior ocorrência de crimes nos últimos cinco anos, conforme registro de ocorrências da Polícia Militar de Santa Catarina. Será apresentada a explicação de como fatores espaciais podem influenciar a ocorrência de crimes na cidade de Laguna e por que certos padrões de crimes acontecem em determinados espaços, em detrimento de outros. A via com maior ocorrência de crimes é a Rua Júlio Maurício, no Bairro Portinho, com registro de 97 ocorrências no últimos cinco anos. Essa via é predominantemente residencial de baixa renda, com baixo grau de integração local e com grande quantidade de pontos de venda de drogas, talvez esse seja o maior motivo da grande número de ocorrências.

A Avenida Calistrato Muller Salles, no trecho compreendido no Bairro Portinho, aparece em 2o lugar, com o registro de 84 ocorrências e no trecho do Bairro Progresso fica em $4^{\circ}$ lugar, com registro de 41 ocorrências. Nesta avenida também percebe-se a monofuncionalidade, mas, neste caso, de estabelecimentos comerciais, ao contrário da Rua Júlia Maurício, a via tem um grande grau de integração local.

Em terceiro lugar, a Avenida Maurílio Kfouri teve registro de 76 crimes nos últimos cinco anos. É a avenida da beira-mar da principal praia de Laguna. Na composição dos usos, predomina os edifícios residenciais, com térreos residenciais e na grande maioria dos casos, garagens. Soma-se ao fato de que a maioria dos apartamentos somente são ocupados no período do verão. Há também a presença de terrenos sem edificações que podem proporcionar áreas inseguras e influenciar na ocorrência de crimes no seu entorno. A avenida apresenta um baixo grau de integração local.

Por último, a Avenida João Pinho, também no Bairro Mar Grosso, teve 37 crimes registrados e apresenta características de usos semelhantes a Avenida Calistrato Muller Salles, com predominância de estabelecimentos comerciais e um médio grau de integração local. As cinco vias acima identificadas são apresentadas nas figuras $9,10,11,12$ e 13, com destaque para seu grau de integração local e imagens caracterizando os seus usos e tipologias edificatórias.

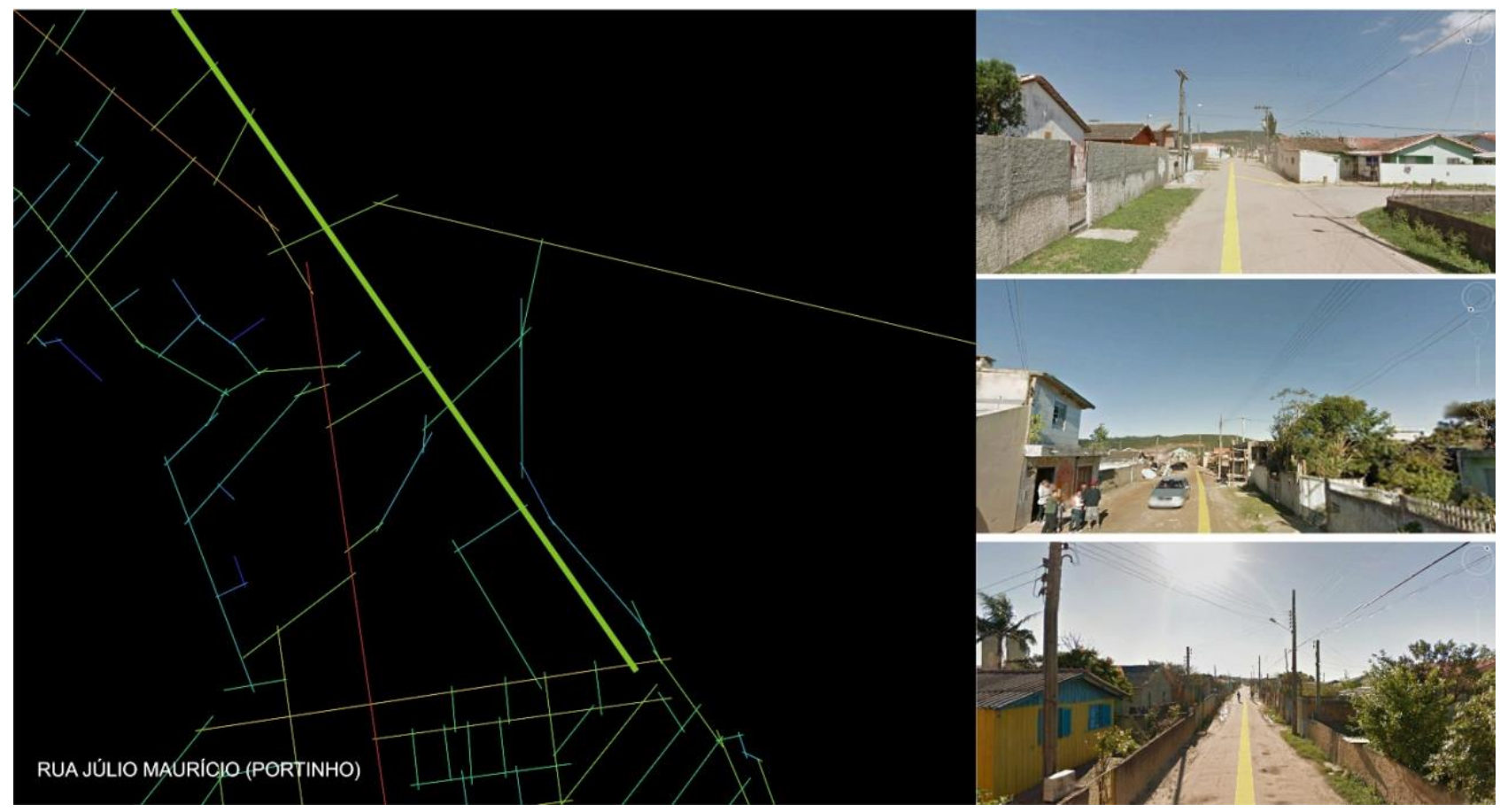

Figura 9 - Rua Júlio Maurício - Bairro Portinho

(Elaboração própria a partir de dados da PMSC (2016), programa Dephtmap e imagens do Google Street View) 


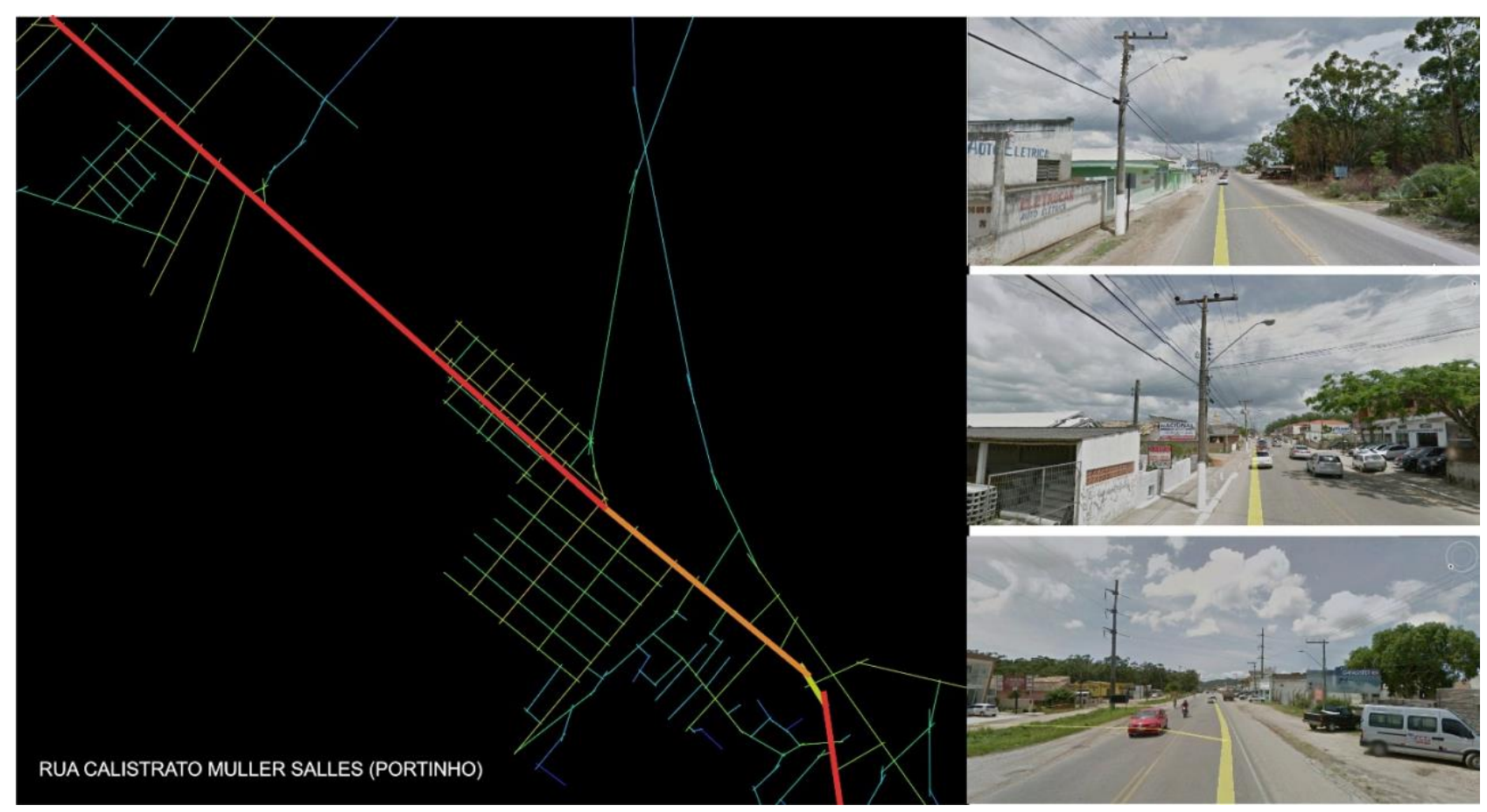

Figura 10 - Avenida Calistrato Muller Salles - Bairro Portinho

(Elaboração própria a partir de dados da PMSC (2016), programa Dephtmap e imagens do Google Street View)

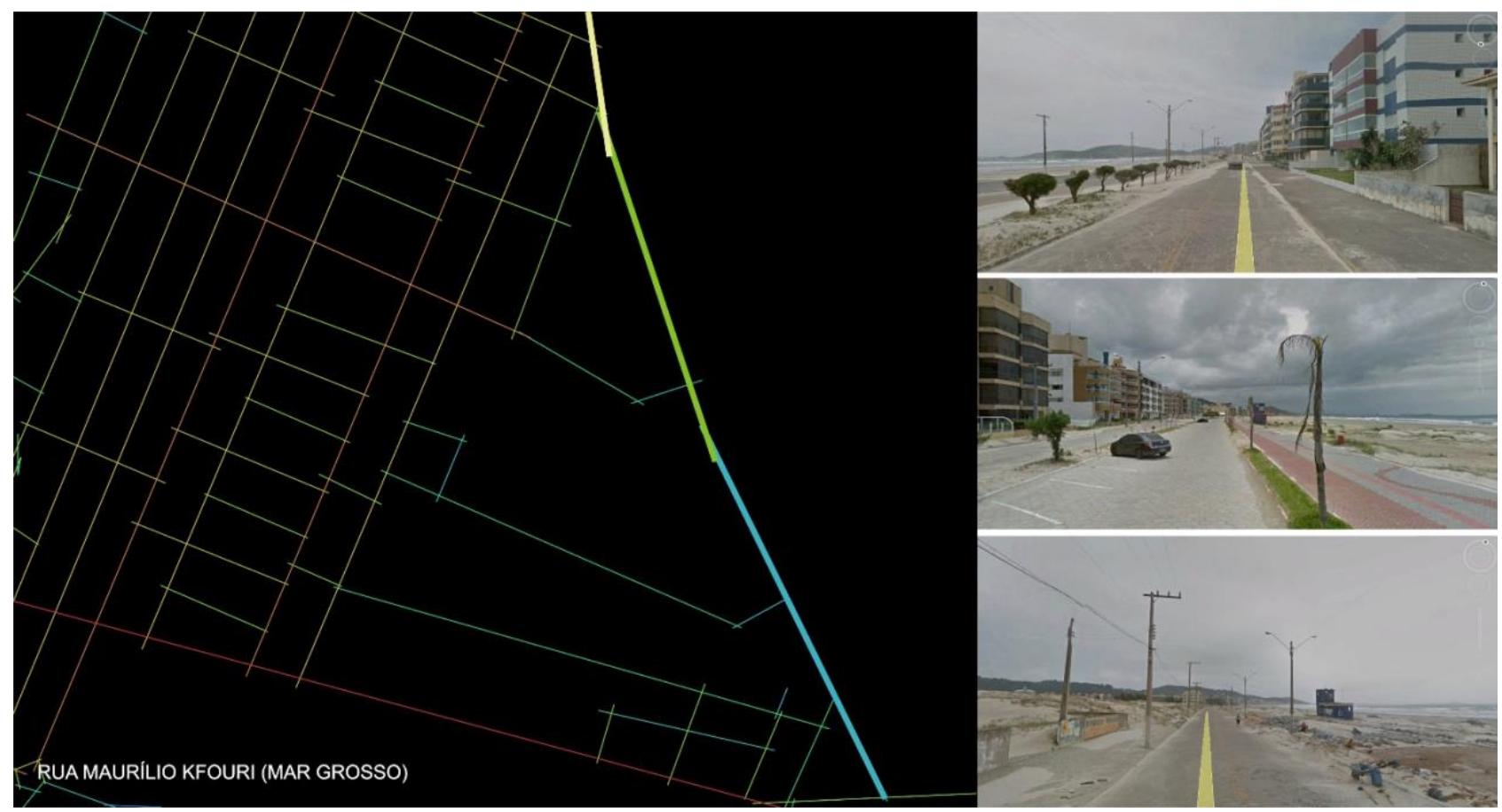

Figura 11 - Avenida Maurílio Kfouri - Bairro Mar Grosso

(Elaboração própria a partir de dados da PMSC (2016), programa Dephtmap e imagens do Google Street View) 


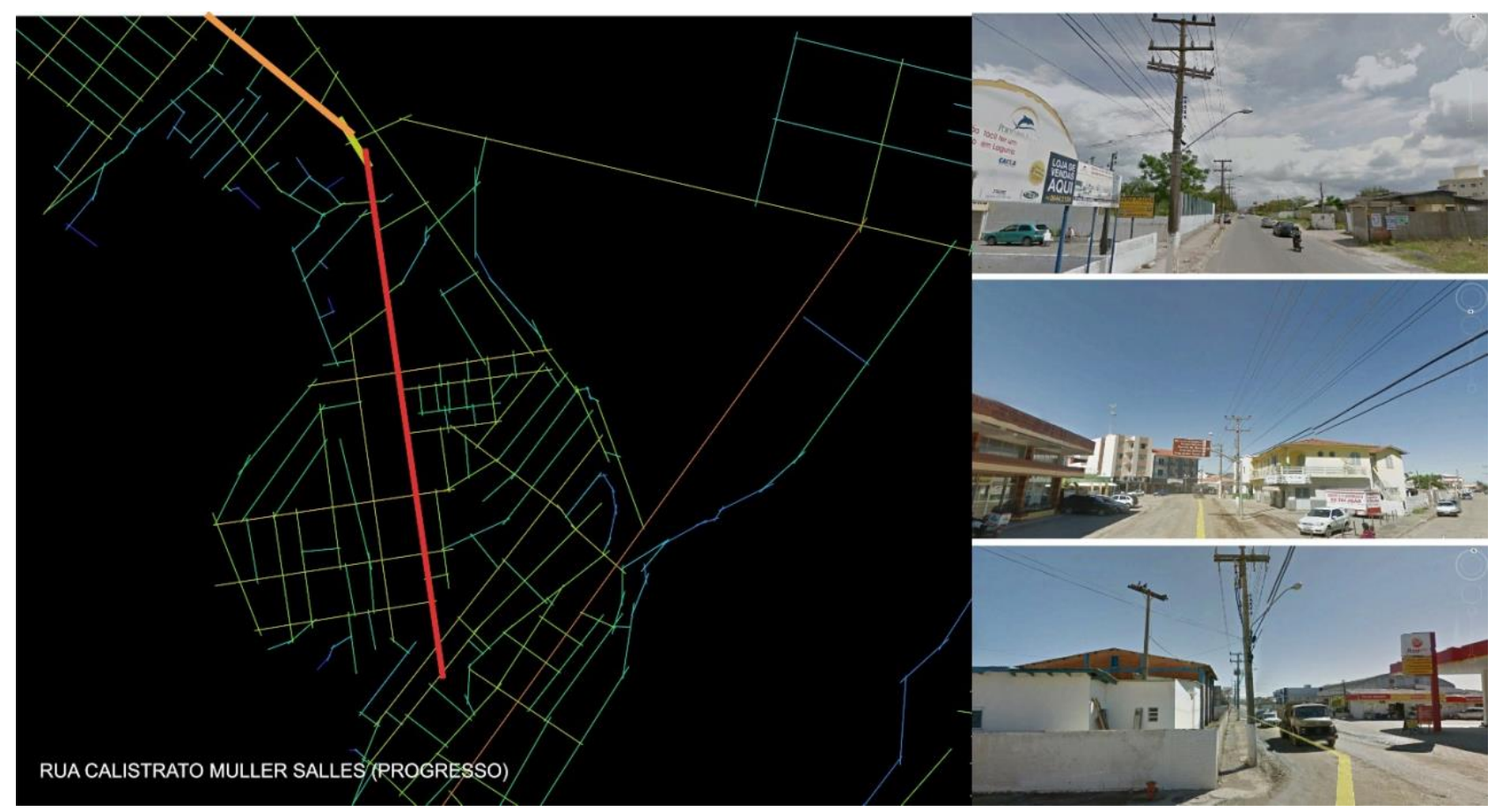

Figura 12 - Avenida Calistrato Muller Salles - Bairro Progresso (Elaboração própria a partir de dados da PMSC (2016), programa Dephtmap e imagens do Google Street View)

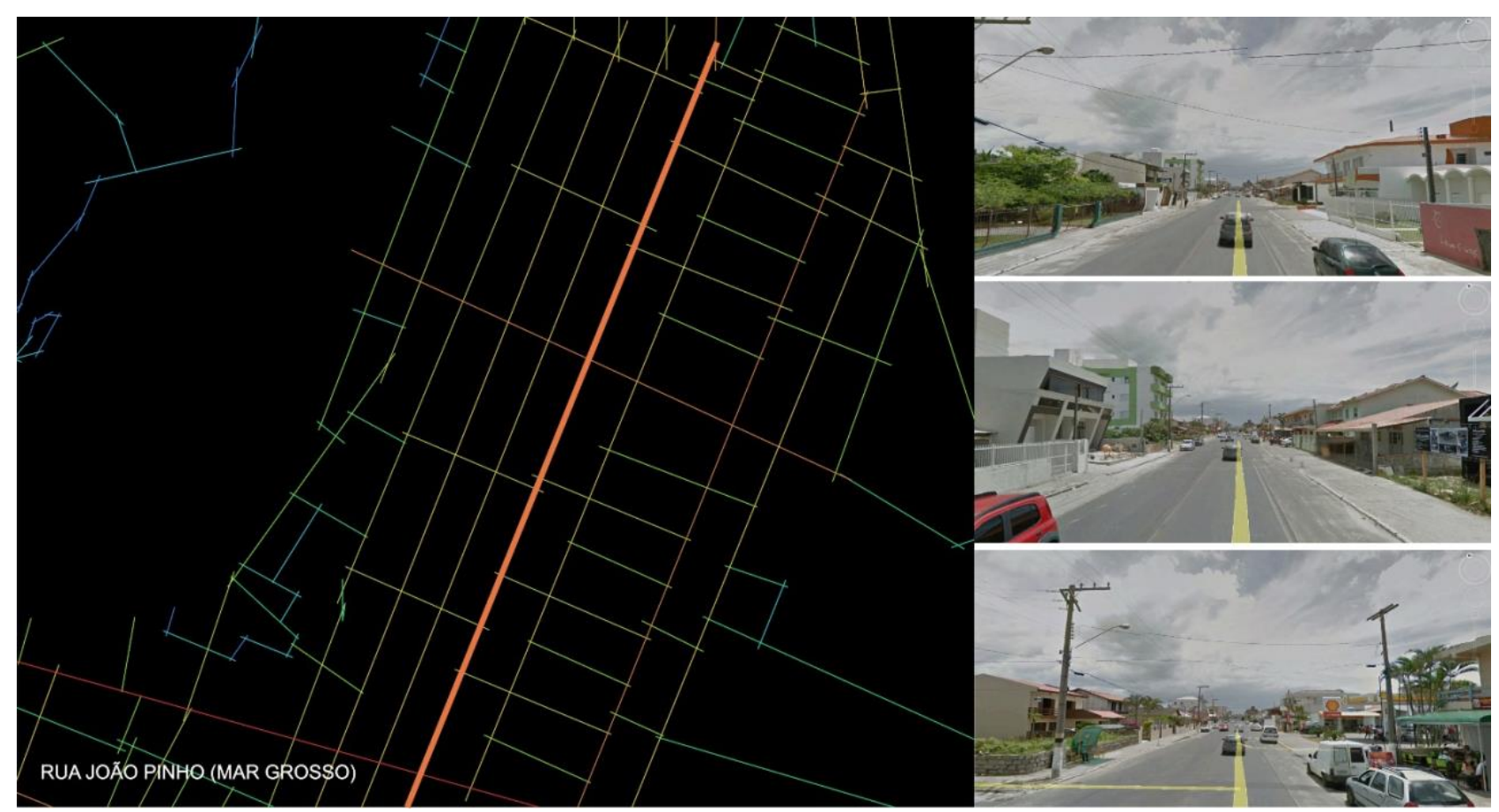

Figura 13 - Avenida João Pinho - Bairro Mar Grosso

(Elaboração própria a partir de dados da PMSC (2016), programa Dephtmap e imagens do Google Street View)

\section{CONSIDERAÇÕES FINAIS}

A motivação desta investigação surgiu para refletir sobre como a configuração espacial afeta os níveis de segurança naqueles lugares que acolhem a vida comunitária de seus habitantes. A pesquisa faz parte da disciplina Estudos Configuracionais Urbanos, realizada no Programa de Pós-Graduação em Arquitetura e Urbanismo da Universidade Federal de Santa Catarina e tem como objetivo encontrar relações entre os elementos formais que busquem um menor grau de ocorrência de crimes. 
As características sintáticas analisadas trouxeram informações relevantes, como a existência na amostra dos crimes de uma maior quantidade proporcional de vias com médio e alto grau de integração, contrariando alguns autores de que os crimes acontecem em vias com menor movimentação de pessoas. A maior parte dos crimes ocorreu em vias com maior integração, mais atrativas e movimentadas.

Entendemos que a segurança deve ser uma espécie de qualidade superior do espaço urbano reunindo as suas melhores qualidades sendo indissociável para a apropriação das pessoas. A identificação do repertório sobre as características configuracionais para a ocorrência de menor número de crimes, define seu nível de relevância para as cidades.

\section{BIBLIOGRAFIA}

CRICHYNO, J. (1996). Uso potencial da vegetação de restinga (Maricá-RJ): critério para seleção de espécies em projetos de paisagismo. II Encontro Nacional de Ensino de Paisagismo em Escolas de Arquitetura e Urbanismo no Brasil, São Paulo.

GEHL, J. (2006). La humanizacion del espacio urbano: la vida social entre los edifícios. Barcelona: Editorial Reverte.

GEHL, J. (2013). Cidades para pessoas. São Paulo: Perspectiva.

HILLIER, B. et al (1983). Space Syntax: a different urban perspective. London: Architecture Jornal.

HILLIER, B., HANSON, J. (1984). The social Logic of Space. Cambridge: University Press.

HILLIER, B., SHU, S. (2002). Do Burglars understand defensive space? New evidence on the relation betweem crime and space. Disponível em http://www.spacesyntax.com. Acesso em: 10 set. 2016

HOLANDA, F. (2002). O espaço de exceção. Brasília: Editora Universidade de Brasília.

HOLANDA, F. (2007). A praga do infinito e a ressurreição do lugar. In C. R. DUARTE et al, O lugar do projeto no ensino e na pesquisa em arquitetura e urbanismo (241-254). Rio de Janeiro: Contra Capa.

HOLANDA, F. (2012). Urbanidade: arquitetônica e social. In D. AGUIAR, V. M. NETTO (orgs.), Urbanidades (163-187). Rio de Janeiro: Folio Digital.

IBGE - Instituto Brasileiro de Geografia e Estatística (2016). Ministério do Planejamento, Orçamento e Gestão. Censo Demográfico 2010. Disponível em: <http://www.ibge.org.br>. Acesso em: 10 set. 2016.

JACOBS, J. (2000). Morte e vida das grandes cidades. São Paulo: Martins Fontes.

VIVAN, M. (2012). Arquitetura, Espaço Urbano e Criminalidade: relações entre o espaço construído sob a ótica da intervisibilidade (dissertação). Orientador Renato T. Saboya. Universidade Federal de Santa Catgarina.

PMSC (2016). Informações estratégicas. Gestão operacional consultada em http://bi.pm.sc.gov.br/QvAJAXZfc/opendoc.htm?document=Aplics\%2FBI\%20PMSC.qvw\&host=QVS\%40ntp $\mathrm{m}$-bi e disponibilizadas em arquivo digital. 